\title{
RESEÑAS DE LIBROS
}

Zurita, Rafael y Camurri, Renato (eds.), Las elites en Italia y en España (1850-1922), Valencia, Universitat de València, 2008, 261 págs.

El presente libro es un obra colectiva fruto del congreso internacional que se celebró en 2006 en la Universidad de Verona bajo el título, Le élites in Italia e in Spagna (1850-1922). En él, Rafael Zurita y Renato Camurri, sus editores, recogen las aportaciones de quince de los mejores especialistas que han consagrado buena parte de su trayectoria profesional a la investigación de las elites políticas y económicas de Italia y España. Nos encontramos, por tanto, ante un trabajo de historia comparada insertado en un marco cronológico que trascurre desde mediados del siglo XIX a la crisis final del constitucionalismo liberal. Y con notable coherencia interna, ya que a diferencia de lo que ocurre en muchas obras de este género, en este caso, Zurita y Camurri han logrado que las ponencias publicadas guarden entre sí una perfecta sintonía. El libro está dividido en tres grandes bloques temáticos. En el primero, sus editores, antes de plantear cuestiones específicas sobre la historia de las elites, recogen cuatro estudios con carácter introductorio en los que le exponen al lector el estado de la cuestión, tanto en Italia como en España. En segundo término se presta atención al papel desempeñado por las elites en la construcción del Estado liberal. Mientras que en los artículos del tercer apartado, que es el más amplio, se analiza la representación y las elites parlamentarias, la relación dialéctica entre el centro y la periferia del poder político, y ya en último lugar, los problemas de las elites y la historia política.

Como se acaba de apuntar, los primeros artículos tienen en cuenta el estado actual de la historiografía. Renato Camurri lo hace en relación a los estudios y perspectivas de investigación de las elites italianas, mientras que Moreno Luzón se centra en el caso de la España liberal. En el primero de los casos, su autor, antes de analizar el estado de los trabajos sobre la elite, señala las razones que retrasaron el desarrollo de la investigación hasta finales de los años setenta. Entre estos obstá- 
culos, los vínculos impuestos por las historiografías de inspiración marxista jugaron un papel destacado, aunque no fue el único factor. La interpretación de los historiadores de izquierda que consideraban que la historia de las elites no era aplicable al estudio de la estructura de la sociedad también entorpeció la investigación, de igual modo como la falta de grandes colecciones y diccionarios biográficos. Sin embargo, el motivo más complejo se debió al incorrecto uso que hicieron las disciplinas históricas de la categoría de elite. Efectuadas las pertinentes aclaraciones metodológicas y etimológicas, Camurri demuestra que las áreas de investigación sobre las que han gravitado los estudios de la elite en las dos últimas décadas han sido la historia social y la política. No obstante, las conclusiones que se recogen presentan un cuadro muy variado y con grandes desequilibrios ya que existen esferas que apenas han sido estudiadas.

Por su parte, Moreno Luzón, que sitúa el surgimiento de la historiografía sobre las elites a mediados del XX, matiza que las investigaciones sobre la clase dirigente generaron en España escaso interés hasta los años ochenta. Seguidamente, y tomando como referencia la producción historiográfica publicada sobre las elites españolas en las dos últimas décadas, Luzón establece cinco rasgos comunes: la predilección por investigar a la elite política, la escasez de colaboraciones entre los historiadores y otros especia- listas en ciencias sociales, el avance de la biografía frente a la prosopografía, la supremacía de los estudios localistas frente a los de ámbito nacional y, en último lugar, la elección de la Restauración y el caciquismo como periodo y cuestión sobre los que se han centrado, en términos generales, el conjunto de estudios sobre las elites. Establecida dicha clasificación, se presta atención al debate historiográfico que se ha ocupado de los lazos entre el poder económico y el político en la España de la Restauración. El autor menciona las interpretaciones de poder de los setenta, es decir, la que separaba las actitudes políticas de las presiones económicas, y la que hacía depender el poder político del económico. Pero también señala la concepción más novedosa, la que está a medio camino entre ambas, ya que esta nueva perspectiva política, aunque reconoce múltiples vínculos, no identifica plenamente las elites políticas y las económicas.

Los dos siguientes trabajos, aunque en diferentes marcos cronológicos, estudian la construcción del estado liberal; Fulvio Cammarano en Italia y Víctor M. Núñez en España. Por lo referido al texto de Cammarano, ofrece algunas claves acerca de cómo la clase política liberal acabó representando la principal articulación institucional de la nueva realidad político-estatal surgida en Italia tras la unificación, siendo la única fuente de legitimación de las frágiles instituciones nacionales. Por ello, el autor examina el fenómeno del 
transformismo bajo la óptica de la defensa de los resultados de la revolución liberal en un contexto europeo, el de las tres últimas décadas del siglo XIX, con grandes tensiones políticas acerca del papel del Parlamento. La ampliación de la base del Estado, completando la nacionalización de los italianos, no caminaba por la asunción de las presiones democráticas, sino por la acentuación del factor administrativo y el papel del Ejecutivo, como ejemplificó Crispi con su lógica de la modernización autoritaria. La derrota colonial en Adua acabó con este proyecto, mostrando además como una parte de la clase política, apoyada por las corrientes democráticas del país, seguía considerando necesario profundizar en las libertades, momento histórico que ya protagonizaría Giolitti.

El profesor Núñez García analiza la relación entre las élites políticas y la construcción del Estado liberal en España. El autor afronta el estudio de la creación del estado liberal desde el punto de vista de las elites de poder. Pero además repasa las diferentes líneas metodológicas que han permitido reconocer en la historia de las elites un objeto de estudio definido con entidad propia. Esto es la metodología prosopográfica y la biográfica. En las décadas centrales del siglo XX, lo individual fue desacreditado en la explicación histórica. Sin embargo, en los últimos tiempos, la biografía ha sido de nuevo incorporada a la historia científica y académica. Y con notable éxito dado el abultado número de obras publicadas. Respecto a la prosopografía, Núñez analiza el género en calidad de método y objetivo investigador. También detalla sus posibilidades y sus limitaciones interpretativas, así como los inconvenientes teóricos y metodológicos que pueden derivar de su aplicación. Luego examina las diferentes formas de entender el Estado liberal que se dieron entre 1850 y 1874. Para ello presenta los fundamentos ideológicos de los grupos políticos que tuvieron la oportunidad de ensayar sus programas, estableciendo las similitudes y los contrastes de sus ideales. En último lugar, el autor, basándose en los resultados de investigaciones sobre las elites, fija algunas de sus particularidades para trazar su perfil socio-profesional, intelectual, económico, etc.

Gian Luca Fruci investiga lo que ha denominado como "los grupos antes de los grupos", es decir, los grupos informales de las asambleas representativas de la Italia liberal. Tomando como punto de partida las instituciones parlamentarias, trata de centrarse en aspectos más específicos a través de los cuales examinar las prácticas y la conducta parlamentaria de los diputados. Con este objetivo hace uso de todos aquellos estudios en los que de manera más o menos sistemática se ha tratado el problema. Partiendo del examen de la notabilidad italiana llega hasta la figura del diputado y las formas en que la elite se organizaba en las instituciones electivas nacionales. 
Establece una tipología y morfología de los grupos parlamentarios que reduce a tres: los "puramente parlamentarios", los denominados "dictadores parlamentarios" y los de "larga duración". Después explica el origen de los partidos y su funcionamiento interno, y para ello hace hincapié en los grupos parlamentarios de larga duración.

Pedro Carasa en su artículo alude en primera instancia a la interpretación económica y política del poder. Sin embargo, no se sitúa en torno a estas teorías, sino que plantea otro enfoque, el de la historia cultural. Afirma que el desarrollo de la historia de las elites será mayor si se examina desde la óptica de la historia cultural. En definitiva, lo que pretende es pasar de la visión prosopográfica y sociológica a una historia cultural del poder. Advierte que explorando este enfoque se alumbrarán nuevos ámbitos oscurecidos a los ojos de la historia económica y social. Con un conjunto de novecientos parlamentarios de época isabelina, Carasa lleva a cabo la relectura de esos datos, pues al hacerlo desde una perspectiva cultural, derivan aspectos hasta entonces ignorados. La historia de una familia y su clan, el valor de algunas profesiones, las formas de movilización o el clientelismo, han de ser analizados desde una perspectiva cultural. Carasa pone de manifiesto la necesidad de estudiar las relaciones informales, pero matiza que ello no puede ser captado desde los planteamientos políticos o económicos. En relación al primer apartado del artículo, el historiador recoge los resultados de una investigación en la que estudia desde una perspectiva sociológica y prosopográfica a ochocientos parlamentarios de la Restauración.

La colaboración de Luigi Musella versa sobre la figura del gran elector, entendiéndolo como vértice de la elite en virtud no sólo de su poder económico y social, sino también de la configuración del espacio público; espacio público valorado como un contexto cultural y de opinión donde surgen un conjunto de ideas que construyen una ideología, una identidad y una autorepresentación. El autor propone superar determinados prejuicios que subrayan los aspectos negativos del clientelismo, para así valorar cómo el notable unía lo público y lo privado, las relaciones personales y familiares con el interés público, poniendo en contacto la periferia y la ciudad. Su poder e influencia derivaban no tanto de sus cualidades personales como de una sólida posición socio-económica que nacía en el contexto de la provincia. El notable desempeñaba así un papel de revisor y dispensador de recursos, estando por encima de su capacidad específicamente política su capacidad de patronato, por la importancia de las gestiones de interés local o en beneficio de sus electores. De todo ello surgiría una clase política escasamente preparada y dispuesta al ministerialismo perpetuo. Así pues, para Musella la circulación entre las elites no funcionaba como un intercambio, sino como 
una mezcla entre los nuevos elementos y los viejos, dando lugar a modelos cuyo éxito se basaba en la cultura civil existente en la sociedad italiana.

Zurita Aldeguer sigue en la línea de los artículos en los que se analizan la representación y las elites parlamentarias. Alude a la dicotomía del poder central y el local como uno de los ejes fundamentales de análisis para estructurar el campo de la historia de las elites y su relación con la construcción del Estado. Los procesos electorales constituyen un escenario privilegiado para examinar la dinámica centroperiférica de las elites liberales. Sobre todo porque a través de estos procesos de representación se puede estudiar el juego de las influencias, el ejercicio del poder y la promoción de las elites. Luego el autor pasa a examinar la trayectoria política de dos representantes de la nueva elite con el objetivo de mostrar la dialéctica de poderes e influencias que contribuyó a moldear el Estado liberal. Los individuos en cuestión son, por una parte, José Posada Herrera, dirigente nacional que deambuló de la derecha a la izquierda dinástica y, por otro, Joaquín Orduña Feliú, un cacique alicantino. Aunque con notables diferencias, Zurita demuestra cómo ambos fueron producto de los cambios operados por la revolución liberal y cómo encarnaron formas diferentes de influencia. El cacique de Guadalest pone de relieve la importancia de las redes clientelares como sustento del Estado liberal. Pero si Or- duña personifica el peso del localismo, Posada encarna el poder central. Esto manifiesta la dialéctica y reciprocidad de ambos poderes.

Fulvio Conti, por su parte, lleva a cabo un triple análisis. En primer lugar, se preocupa del cambio en la historiografía italiana que motivó un interés por una nueva historia social centrada en la burguesía, la aristocracia, las elites y sus formas de relación, lugares de encuentro y ocio. En ese cambio estuvo influenciada por los estudios de la tradición francesa (Agulhon y la sociabilité) y la nueva historia social alemana (Habermas y el nacimiento de la opinión pública y de la sociedad civil). En ambos casos, la densidad de las formas asociativas es el núcleo explicativo esencial, con diversos matices. En segundo lugar, el autor se preocupa por el desarrollo del fenómeno asociativo burgués en Italia, que se produjo con una cronología diferente a la de la Europa desarrollada, estando caracterizado por su gran fragmentación y acentuado localismo, reflejo, en parte, del proceso de unificación nacional. En un tercer bloque se estudia el impacto de la unificación que, gracias a la extensión del Estatuto Albertino de 1848, provocó un rápido crecimiento del asociacionismo que permitió que surgieran en los años setenta y ochenta asociaciones con un carácter menos exclusivo y abiertas a las clases medias y grupos populares. El espíritu de asociación, antiguo privilegio de la nobleza y la alta burguesía, acabó así 
convertido en práctica habitual de muchos ciudadanos mostrando con ello el triunfo del modelo burgués de sociabilidad.

Elena Maza Zorrilla, tras realizar un repaso historiográfico referido a los estudios de la sociabilidad y la acción colectiva, considera el periodo comprendido entre 1850 y 1923 desde el binomio elites frente a asociacionismo como marco explicativo, valorando tanto las cortapisas legales que dificultaron "desde arriba" un desarrollo asociativo en libertad en España como las líneas generales del asociacionismo que, pese a las trabas, se dio. Además, reflexiona acerca de la problemática de las fuentes utilizadas en estas investigaciones, caracterizadas por su dispersión, fragmentación y silencios; aspectos que quizás expliquen la tardanza autóctona en el abordaje de este tipo de estudios. Resalta de esta investigación el choque entre el inmovilismo político y las transformaciones sociales y culturales, lo que no fue óbice para que elementos anteriores, como la fórmula mutualista, mantuvieran su operatividad, mostrando con ello una doble vertiente; si en algunos casos contribuyó al aprendizaje político del movimiento obrero, en otros fue cómplice de la consolidación del sistema, paliando sus carencias. En síntesis, la autora muestra el asociacionismo como un prisma básico para observar las preocupaciones de la sociedad civil, destacando además cómo el tejido asociativo de las primeras décadas de siglo mostraba tanta continuidad como cambio.

Andrea Giuntini reflexiona sobre el papel de los empresarios entre la primera y la segunda industrialización italiana, enmarcado en el contexto de la proliferación de estudios relativos a esa élite económica, investigaciones en las que ha tenido gran importancia la biografía colectiva. A su vez, realiza un sucinto repaso relativo a diversas cuestiones, aludiendo, por ejemplo, a la pluralidad de empresarios que operaron en la economía italiana o a diversas estimaciones cuantitativas relativas a la presencia de empresas y empresarios desde 1878 hasta 1981. Se destaca también el impacto del proteccionismo inaugurado en la década de los ochenta del siglo XIX, que contribuyó al despegue industrial italiano gracias a la intervención del Estado. Asimismo aborda el papel de la industria eléctrica y su desigual asentamiento en el territorio italiano, el rol jugado por los empresarios extranjeros (fundamentalmente suizos y alemanes), el papel de los municipios como generadores de formas de empresariado novedosas o la amplia presencia de la empresa pública desde el periodo de entreguerras. Finalmente, el artículo abordará el boom económico de posguerra, desde 1956 a 1963, y los factores que lo permitieron, planteando convenientemente el fundamental debate acerca de la influencia norteamericana en las prácticas empresariales italianas. 
Jesús Millán aborda la relación entre las elites políticas y los cambios sociales en la España liberal a través del caso de la Restauración, cuyo fracaso, y por ende, el de la Segunda República, han sido considerados como "punto de llegada" de una larga etapa anterior en la que se atribuía al liberalismo la responsabilidad de haber consolidado los derechos feudales en forma de propiedad burguesa de la tierra. Esa transformación de la propiedad descalificaba netamente al liberalismo del siglo XIX, identificándose política liberal con supervivencia de las elites y opresión de clase, formulación que gozó de amplio predicamento historiográfico, también durante el franquismo y la historiografía reciente. Sin embargo, Millán apuesta por replantear esos supuestos, a la luz de los últimos estudios, puesto que el triunfo del liberalismo no fue una operación favorable a la aristocracia, ni el conjunto de la política liberal se inscribe en una corriente favorable a los propietarios y alejada de las aspiraciones de las clases populares. La alteración de la escala social o el cuestionamiento del régimen señorial mostrarían que el liberalismo perjudicó a la Iglesia y a los sectores señoriales, mientras que los cambios en la estructura agraria revelarían que la política realizada por las elites no significó una inercia a favor de un bloque homogéneo de propietarios. Así pues, el liberalismo, pese a rechazar la democracia, podía enlazar con la base de la sociedad, aunque a partir del Sexenio se generara un importante deterioro de la legitimación de sus elites. Por todo ello, el fracaso de la Restauración, según Millán, intentó atribuirse al lastre de un pasado denostado que los estudios actuales no deberían contemplar bajo la misma óptica.

Paolo Pombeni se preocupa por la relación entre la autoridad social y el poder político a través del enfoque teórico de las ideas-tipo weberianas. Así, aborda el problema de la relación entre autoridad y poder, reflexionando sobre el origen de diversos términos como "sociedad civil" y su relación con los conceptos de "poder", "autoridad" y "poder legítimo". Esta destacada atención a esta problemática se justifica en el papel angular que el autor otorga a la relación entre autoridad social y poder político en las sociedades contemporáneas. Identificará tres ideas-tipo para esa relación, la referida al sistema de notables, una idea-tipo eclesiástica (organización de la autoridad política vinculada a una institución para la salvación, que pone en contacto el mundo de la experiencia y el de la esperanza) y otra de tipo burocrático-distributiva, subdividida a su vez en tres mecanismos de activación (político, sindical o de utilidad social) donde el poder proviene de la capacidad para crear equilibrio en la esfera social con la distribución de recursos producidos en la esfera política, generando con ello fidelidades. Si la primera y tercera función fallan, el Estado siempre podrá huir hacia la segunda, 
explicando en parte el éxito que tuvo el desafío fascista ante la crisis de los sistemas liberales. Pombeni desarrollará estas cuestiones abordando además las religiones civiles y la dificultad de éstas para establecerse fuera del totalitarismo.

Xosé R. Veiga Alonso compara a las elites italianas y españolas entre 1850 y 1922. Tras una reflexión acerca del contenido de la palabra elite y la propia historicidad, a menudo olvidada, de la teoría de elites, el autor valora las coincidencias entre ambos casos, cuyo pensamiento político coincidía en la desconfianza respecto a la capacidad de la población para intervenir en la vida pública a la par que el temor a que su intervención pudiese derivar en la democracia. La política no debía ser más que una derivación lógica de la posición ocupada en el seno de la comunidad, un deber más de la elite social y ante todo, una cuestión de amigos, de ahí que frente al carácter artificial de los partidos se apostara por otros modos de organización más naturales, como era la familia y la clientela. El impacto de los cambios que el final del siglo conllevó, con la aparición de una política de masas, las críticas al parlamentarismo adulterado y las consecuencias de las crisis exteriores, desembocaría en sendos regímenes antiliberales y antiparlamentarios en los que el consenso de la elite sustituía a la lucha democrática por el electorado. Finalmente, la Gran Guerra significaría el manifiesto triunfo de la política de masas, pero como se comprobaría en ambos países, ello no significó el triunfo de la democracia, sino la proclamación de sendos cirujanos de hierro.

Finalmente, Alfio Signorelli sintetiza los resultados de los estudios de historia comparada entre Italia y España a partir de la renovada fluidez de las relaciones entre estudiosos de ambos países en los últimos quince años; siendo el libro aquí reseñado una prueba manifiesta. Destaca como aspecto común a ambas historiografías el pesimismo; si en España se aludía a la ausencia de una verdadera revolución burguesa, en Italia contaban con la noción de "rivoluzione mancata". El cambio de perspectiva dejaría paso a interpretaciones triunfalistas que reivindicaron la originalidad de ambas vías nacionales hacia la modernización. Actualmente, para Signorelli prevalece una actitud más equilibrada basada en la práctica de la comparación como medio para valorar ambos fenómenos en su especificidad, acompañada del regreso del interés por la historia política; una historia política que se ha extendido a los aspectos socioculturales de la política, las mentalidades, representaciones y prácticas discursivas. Bajo esa nueva óptica, son esenciales los debates referidos a la cronología, apostándose por una ampliación temporal de las investigaciones sobre la burguesía liberal hasta sus orígenes dieciochescos, para así reconsiderar fenómenos como el caciquismo y el clientelismo desde una perspectiva 
que no esté determinada únicamente por la época liberal.

ANTONIO J. PIQUERES DÍEZ VÍCTOR SÁNCHEZ MARTÍN Universidad de Alicante

Jiménez de Aberasturi Corta, Juan Carlos y Moreno Izquierdo, Rafael, Al servicio del extranjero. Historia del Servicio Vasco de Información (19361943), Madrid, Antonio Machado Libros, 2009, 549 págs.

El autor principal de la obra, Juan Carlos Jiménez de Aberasturi es doctor en Historia por la Universidad del País Vasco, director del Archivo Municipal de Errenteria, así como de la Biblioteca y del Servicio Editorial. Creó y dirigió durante años el Centro de Documentación de Historia Contemporánea del País Vasco (Eusko Ikaskuntza) y es experto en historia oral y en fuentes documentales para la Historia contemporánea de Euskadi, materia en la que colabora con el Gobierno Vasco y con el Ministerio de Cultura, en el que además es miembro del Consejo Superior de Archivos desde 2005. Autor de una extensa producción bibliográfica, entre la que cabe destacar La guerra en Euskadi (1978, 2007), La huelga general de mayo de 1947 (1991), De la derrota a la esperanza: políticas vascas durante la II Guerra Mundial (1999), De la Guerra Civil a la Guerra Fría. Cronología de historia contemporánea del País
Vasco (2001). Si hubiera que buscar un rasgo caracterizador de las investigaciones de Jiménez de Aberasturi, la originalidad y la dificultad intrínseca del tema constituirían en nuestra opinión dicho rasgo. En lugar de transitar las reposadas sendas de lo conocido, siempre ha preferido abrir nuevas vías sin importarle la dificultad de la tarea. Experto en hallar nuevos veneros documentales, aunque haya tenido que irse como en este caso hasta los Archivos Nacionales de Estados Unidos (Washington), del Reino Unido (Londres) y de Francia (París); así como en la recuperación de testimonios de los supervivientes de los hechos investigados, Jiménez de Aberasturi ha proporcionado con ellos nuevos enfoques a la Historia con mayúsculas. Hace no muchos años dio a la imprenta un interesante ensayo sobre la Red Comete (En pasant la Bidassoa: le Resau Comete au Pays Basque, 1941-1944), un heroica red secreta sobre la que nadie había investigado hasta entonces, dedicada a rescatar pilotos de guerra aliados caídos en la Europa ocupada y que, a través del Bidasoa, con la ayuda de algunos ciudadanos de ambos lados de la frontera, eran introducidos en España, y desde aquí enviados a Londres, Lisboa o Gibraltar, fuera del alcance de las fuerzas alemanas que procuraban su detención.

Del segundo autor, Rafael Moreno Izquierdo, poco puede decirse, ya que éste es su segundo libro y primera incursión en el territorio de la historia. 